\title{
Establishment and Verification of Scoring System for Colorectal Adenoma Recurrence
}

\section{Xujie $\mathrm{Xi}^{*}$ \\ Zhaoli Fu* \\ Tianwen Liu* \\ Yanfeng Lin \\ Wenbin Wu \\ Jianmin $\mathrm{Li}$ \\ Ming Luo \\ Beiping Zhang}

Department of Spleen and Stomach Diseases, The Second Affiliated Hospital of Guangzhou University of Traditional Chinese Medicine, Guangzhou, People's Republic of China

*These authors contributed equally to this work
Correspondence: Beiping Zhang

Department of Spleen and Stomach

Diseases, The Second Affiliated Hospital

of Guangzhou University of Traditional

Chinese Medicine, No. III Dade Road,

Yuexiu District, Guangzhou, 510120,

Guangdong Province, People's Republic of China

Tel +86-13602762766

Email beipingzhang@2Icn.com
Objective: The purpose of this study was to establish and verify a risk-scoring system for colorectal adenoma recurrence.

Methods: A total of 359 patients with colorectal adenoma who underwent polypectomy from October 2017 to December 2018 were included in this retrospective study. Information including taking traditional Chinese medicine, demographic characteristics, adenoma characteristics were collected. The patients will review the colonoscopy one year after surgery. The patients were divided into a modeling cohort (216 cases) and a model validation cohort (143 cases) according to the ratio of 6:4. Modeling and model verification were performed by logistic regression, ROC curve, nomogram (calibration chart) and other methods.

Results: After adjusting for confounding factors by logistic regression, it was found that taking Chinese medicine, the number, size, site, pathological type and morphology of adenoma were independent influencing factors for the recurrence of colorectal adenoma. The area under the ROC curve (AUC) in the model validation cohort of established risk scoring system was 0.771 (95\% CI: 0.694-0.847), indicating that there was good consistency.

Conclusion: The established risk prediction model of colorectal adenoma recurrence and its risk scoring system performed well and had high predictive value.

Keywords: colorectal adenoma, recurrence, prediction model, risk scoring system

\section{Introduction}

There are many known risk factors for the recurrence of colorectal adenoma. The basic characteristics of adenoma is an important factor affecting recurrence. Any one of the three points including a diameter of $\geq 10 \mathrm{~mm}$, more than $25 \%$ of the villi, and high-grade dysplasia is considered as advanced adenoma. Winawer et al believe that advanced adenoma has a higher possibility of canceration and recurrence. ${ }^{1}$ In a meta-analysis, polyp size and incomplete resection were found to be the main predictors of adenoma recurrence. ${ }^{2}$ Moreover, elderly age, high body mass index (BMI), smoking, excessive alcohol intake and low fiber diet are considered to increase the probability of adenoma recurrence. ${ }^{3-8}$

Although there are many factors that affect the recurrence of adenomas, no research has proposed a clinical scoring system for adenoma recurrence. Aspirin, COX-2 inhibitors, vitamin D, calcium, folic acid and metformin have been shown to prevent recurrence of adenoma. ${ }^{9-12}$ However, the preventive effect is still controversial, and long-term use of these drugs has obvious side effects. ${ }^{13} \mathrm{~A}$ recent study showed that berberine, a traditional Chinese patent medicine, has a certain effect on the prevention of adenoma recurrence in colorectal cancer, ${ }^{14}$ which has 
aroused the enthusiasm of scholars for the research of traditional Chinese medicine on the recurrence of adenoma. We have achieved good clinical effect in the prevention and treatment of recurrence of colorectal adenoma with traditional Chinese medicine. ${ }^{15}$

In this study, a retrospective case study method was adopted, and the clinical risk score method was innovatively combined to establish the risk prediction model and scoring system of colorectal adenoma recurrence to systematically and quantitatively evaluate the influence of traditional Chinese medicine "polyp Xiao" and other risk factors on the recurrence of colorectal adenoma.

\section{Subjects and Methods Subjects}

From October 2017 to December 2018, patients with colorectal polyps detected by colonoscopy and treated under endoscopy in the digestive endoscopy center of Guangdong Hospital of traditional Chinese medicine were included in this retrospective case-control study. The patients were confirmed as adenoma by postoperative pathology. All patients were informed and signed informed consent voluntarily. This study was approved by the ethics committee of the Second Affiliated Hospital of Guangzhou University of traditional Chinese and complied with the guidelines outlined in the declaration of Helsinki were followed. The written consent was received from all participants. Exclusion criteria: (1) lack of postoperative pathological examination results; (2) patients with inflammatory bowel disease, familial hereditary polyposis, P-J syndrome, invasive cancer; (3) patients who have used drugs with potential treatment for colorectal adenoma (aspirin, folic acid, vitamin D, calcium, etc.); (4) patients with serious underlying diseases, such as heart, kidney and hematopoietic system; (5) Patients who may be allergic to the ingredients of the drug.

\section{Sample Size Estimation}

Those with recurrence of adenoma were selected as the case group, and those without recurrence of adenoma were selected as the control group. Expected odds ratio (OR) was 0.5 . The proportion of patients who took traditional Chinese medicine in the two groups was about $50 \%$, with $\alpha=0.05, \beta=0.10$. There was equal sample size in the case group and control group. By substituting the above conditions into PASS11.0 software, the sample sizes of the two groups were 182 cases, respectively. Finally, a total of 359
Cases were included in the study, accounting for $98.6 \%$, including 193 cases $(53.76 \%)$ in recurrence group and 166 cases $(46.24 \%)$ in non-recurrence group.

\section{Observation Indexes}

When the patients were enrolled, their general information was recorded, including gender, age, BMI, past medical history, whether to use traditional Chinese medicine, the number, size, location, pathological nature of adenomas, and whether to take traditional Chinese medicine to eliminate polyps. The main outcome was whether there was the recurrence of colorectal adenoma in all patients 1 year after operation. Recurrence was defined as 1 or more polyps found by colonoscopy 1 year after operation, and the recurrence was confirmed by pathology.

\section{Statistical Analysis}

Those 359 patients were divided into recurrence prediction model cohort and recurrence verification model cohort at a ratio of 6:4 after setting random number seed. Among them, 216 cases were used in the recurrence risk prediction model cohort, and 143 cases were used in the model verification cohort and evaluation of the performance of the recurrence prediction model. $\chi^{2}$ test was used to compared the counting data between groups, and $t$ test (or rank sum test) was used to compare the measurement data. A 5-fold cross-validated logistics regression model was used to establish a recurrence scoring model and a nomogram was drawn. ROC curve and calibration map were used to evaluate the performance of recurrence prediction model. SPSS 24 software and R software were used for statistical analysis, and the test level was $\alpha=0.05$.

\section{Results}

\section{Baseline Information of Modeling Cohort and Model Validation Cohort}

There was no significant difference in the basic demographic characteristics between the modeling group and model validation group for recurrence of colorectal adenoma $(\mathrm{P}>$ 0.05). It was suggested that the recurrence rate of patients taking traditional Chinese medicine was lower than that of patients without Chinese medicine in both modeling group and model validation group $\left(\chi^{2}=14.759, P<0.001 ; \chi^{2}=\right.$ $4.005, P<0.05)$. Moreover, in the model validation group, the recurrence rate of patients aged $\geq 60$ years was relatively high $\left(\chi^{2}=6.013, P<0.05\right)$ (Table 1$)$. 
Table I Baseline Analysis of Modeling Cohort and Model Validation Cohort

\begin{tabular}{|c|c|c|c|c|c|c|c|c|}
\hline \multirow[t]{2}{*}{ Items } & \multicolumn{2}{|c|}{ Modeling Cohort $(n=2 \mid 6)$} & \multirow[t]{2}{*}{$\chi^{2}$} & \multirow[t]{2}{*}{$\mathbf{P}$} & \multicolumn{2}{|c|}{ Model Validation Cohort $(n=\mid 43)$} & \multirow[t]{2}{*}{$\chi^{2}$} & \multirow[t]{2}{*}{$P$} \\
\hline & Recurrence & Non-Recurrence & & & Recurrence & Non-Recurrence & & \\
\hline Ages & & & 0.064 & 0.800 & & & 6.013 & 0.014 \\
\hline$<60$ & $56(48.3)$ & $50(50.0)$ & & & $32(4 \mid .6)$ & $4 I(62.1)$ & & \\
\hline$\geq 60$ & $60(51.7)$ & $50(50.0)$ & & & $45(58.4)$ & $25(35.7)$ & & \\
\hline Gender & & & 2.413 & 0.120 & & & 0.975 & 0.323 \\
\hline Female & $55(47.4)$ & $58(58.0)$ & & & $31(40.3)$ & $32(48.5)$ & & \\
\hline Male & $61(52.6)$ & $42(42.0)$ & & & $46(59.7)$ & $34(51.5)$ & & \\
\hline BMI & & & 1.395 & 0.498 & & & 3.278 & 0.194 \\
\hline Emaciation & $8(6.9)$ & II (II.0) & & & $8(10.4)$ & 14 (21.2) & & \\
\hline Normal & $69(59.5)$ & $60(60.0)$ & & & $52(67.5)$ & $38(57.6)$ & & \\
\hline Obesity & $39(33.6)$ & $29(29.0)$ & & & $17(22.1)$ & 14 (21.2) & & \\
\hline Smoking & & & 0.532 & 0.466 & & & 0.152 & 0.696 \\
\hline No & $93(80.2)$ & $84(84.0)$ & & & $61(79.2)$ & $54(81.8)$ & & \\
\hline Yes & $23(19.8)$ & $16(16.0)$ & & & $16(20.8)$ & $12(18.2)$ & & \\
\hline Drinking & & & 1.089 & 0.297 & & & 0.255 & 0.613 \\
\hline No & $106(91.4)$ & $95(95.0)$ & & & $72(93.5)$ & $63(95.5)$ & & \\
\hline Yes & $10(8.6)$ & $5(5.0)$ & & & $5(6.5)$ & $3(4.5)$ & & \\
\hline \multicolumn{3}{|c|}{ Hypertension } & 0.325 & 0.569 & & & 0.846 & 0.358 \\
\hline No & $83(71.6)$ & $75(75.0)$ & & & $53(68.8)$ & $50(75.8)$ & & \\
\hline Yes & $33(28.4)$ & $25(25.0)$ & & & $24(31.2)$ & $16(24.2)$ & & \\
\hline \multicolumn{3}{|c|}{ Diabetes mellitus } & 0.010 & 0.922 & & & 0.192 & 0.661 \\
\hline No & $106(91.4)$ & $91(91.0)$ & & & $67(87.0)$ & $59(89.4)$ & & \\
\hline Yes & $10(8.6)$ & $9(9.0)$ & & & $10(13.0)$ & $7(10.6)$ & & \\
\hline \multicolumn{3}{|c|}{ Hyperlipidemia } & 2.147 & 0.143 & & & 0.370 & 0.543 \\
\hline No & $95(81.9)$ & $89(89.0)$ & & & $68(88.3)$ & $56(84.8)$ & & \\
\hline Yes & $21(18.1)$ & II (II.0) & & & $9(11.7)$ & $10(15.2)$ & & \\
\hline \multicolumn{3}{|c|}{ Gallbladder diseases } & 0.898 & 0.343 & & & 0.078 & 0.780 \\
\hline No & $105(90.5)$ & $94(94.0)$ & & & $71(92.2)$ & $60(90.9)$ & & \\
\hline Yes & II (9.5) & $6(6.0)$ & & & $6(7.8)$ & $6(9.1)$ & & \\
\hline \multicolumn{3}{|c|}{ History of intestinal polyps } & 0.894 & 0.344 & & & 0.022 & 0.882 \\
\hline No & $84(72.4)$ & $78(78.0)$ & & & $58(75.3)$ & $49(74.2)$ & & \\
\hline Yes & $32(27.6)$ & $22(22.0)$ & & & $19(24.7)$ & $17(25.8)$ & & \\
\hline \multicolumn{3}{|c|}{ Family history of colorectal cancer } & 0.082 & 0.775 & & & 2.627 & 0.105 \\
\hline No & $113(97.4)$ & $98(98.0)$ & & & 74 (96.I) & $66(100)$ & & \\
\hline Yes & $3(2.6)$ & $2(2.0)$ & & & $3(3.9)$ & $0(0)$ & & \\
\hline Medicine & & & 14.759 & $<0.001$ & & & 4.005 & 0.045 \\
\hline No & $7 \mid(6 \mid .2)$ & $35(35.0)$ & & & $49(63.6)$ & 31 (47.0) & & \\
\hline Yes & $45(38.8)$ & $65(65.0)$ & & & $28(36.4)$ & $35(53.0)$ & & \\
\hline
\end{tabular}




\section{Analysis of Adenoma Characteristics Between Modeling Cohort and Model Validation Cohort}

In the modeling cohort, there were significant differences in the number, size, location, pathology and morphology of adenomas between the recurrent group and the nonrecurrence group $(P<0.05)$. In the model validation cohort, there were significant differences in the number, size and location of adenomas between the recurrent group and the non-recurrence group $(P<0.05)$ (Table 2$)$.

\section{Analysis of Influencing Factors of Recurrence in Modeling Cohort}

By univariate logistic regression analysis, it was found that there were statistically significant differences in the outcome of recurrence among the patients in the modeling cohort, such as whether taking traditional Chinese medicine, the number, size, site, pathological types and the morphology of adenomas $(P<0.05)$. The above factors were incorporated into the logistic regression model, we found that age and adenoma site were confounding factors after excluding the mutual influence of various related factors. However, whether taking traditional Chinese medicine, the number, size, pathological types and the morphology of adenomas were the independent influencing factors of adenoma recurrence. Moreover, the recurrence probability of patients taking traditional Chinese medicine is 0.245 times that of not taking traditional Chinese medicine (95\% CI: 0.119-0.501) (Table 3).

\section{Establishment of Risk Scoring System Based on Modeling Cohort}

The risk score system was established and nomogram was drawn according to the seven risk factors in Tables 1 and 3 , including age, whether taking traditional Chinese medicine, the number, size, site, pathological types and the morphology of adenomas. The sub-score of each sub-item can be obtained from the column corresponding to the above score for each categorical variable, and the recurrence risk ratio of the bottom column can be calculated after the total score is calculated (Figure 1).

\section{Verification of Risk Scoring Model}

The Hosmer and Lemeshow Test $(=7.940, \mathrm{P}>0.05)$ in the logistic regression model of this established risk scoring

Table 2 Analysis of Adenoma Characteristics Between Modeling Cohort and Model Validation Cohort

\begin{tabular}{|c|c|c|c|c|c|c|c|c|}
\hline \multirow[t]{2}{*}{ Adenoma Characteristics } & \multicolumn{2}{|c|}{ Modeling Cohort $(n=2 \mid 6)$} & \multirow[t]{2}{*}{$\chi^{2}$} & \multirow[t]{2}{*}{$P$} & \multicolumn{2}{|c|}{ Model Validation Cohort $(n=\mid 43)$} & \multirow[t]{2}{*}{$\chi^{2}$} & \multirow[t]{2}{*}{$P$} \\
\hline & Recurrence & Recurrence & & & Recurrence & Recurrence & & \\
\hline Number & & & 11.610 & 0.001 & & & 16.016 & $<0.001$ \\
\hline $1-3$ & $7262.1)$ & $83(83.0)$ & & & $46(59.7)$ & $59(89.4)$ & & \\
\hline$>3$ & 44 (37.9) & $17(17.0)$ & & & $31(40.3)$ & $7(10.6)$ & & \\
\hline Size & & & 14.642 & 0.001 & & & 16.619 & $<0.001$ \\
\hline $\mathrm{I}-5 \mathrm{~mm}$ & II (9.5) & $19(19.0)$ & & & $8(10.4)$ & $20(30.3)$ & & \\
\hline $6-9 \mathrm{~mm}$ & $46(39.7)$ & $55(55.0)$ & & & $28(36.4)$ & $31(47.0)$ & & \\
\hline$\geq 10 \mathrm{~mm}$ & $59(50.9)$ & $26(26.0)$ & & & $4 I(53.2)$ & $15(22.7)$ & & \\
\hline Site & & & 8.946 & 0.011 & & & 13.694 & 0.001 \\
\hline Left hemicolon & $33(28.4)$ & $37(37.0)$ & & & $21(27.3)$ & $27(40.9)$ & & \\
\hline Right hemicolon & $24(20.7)$ & $32(32.0)$ & & & $18(23.4)$ & $26(39.4)$ & & \\
\hline Whole colon & $59(50.9)$ & $31(31.0)$ & & & $38(49.4)$ & $13(19.7)$ & & \\
\hline Pathology of adenoma & & & 16.096 & $<0.001$ & & & 3.530 & 0.171 \\
\hline Tubular adenoma & $78(67.2)$ & $90(90.0)$ & & & $54(70.1)$ & $55(83.3)$ & & \\
\hline Villous adenoma & II (9.5) & $3(3.0)$ & & & $5(6.5)$ & $3(4.5)$ & & \\
\hline Mixed adenoma & $27(23.3)$ & $7(7.0)$ & & & $18(23.4)$ & $8(12.1)$ & & \\
\hline Adenoma morphology & & & 6.264 & 0.044 & & & 3.991 & 0.136 \\
\hline Artie & $10(8.6)$ & $15(15.0)$ & & & $8(10.4)$ & $6(9.1)$ & & \\
\hline Pedicle & $15(12.9)$ & $22(22.0)$ & & & $4(5.2)$ & $10(15.2)$ & & \\
\hline Flat eminence & 91 (78.4) & $63(63.0)$ & & & $65(84.4)$ & $50(75.8)$ & & \\
\hline
\end{tabular}


Table 3 Analysis of Influencing Factors of Recurrence in Modeling Cohort

\begin{tabular}{|c|c|c|c|c|}
\hline \multirow[t]{2}{*}{ Adenoma Characteristics } & Univariate Analysis & \multirow[t]{2}{*}{$P$} & \multirow{2}{*}{$\begin{array}{l}\text { Multivariate Analysis } \\
\text { OR }(95 \% \mathrm{Cl})\end{array}$} & \multirow[t]{2}{*}{$P$} \\
\hline & OR $(95 \% \mathrm{Cl})$ & & & \\
\hline \multicolumn{5}{|l|}{ Medicine } \\
\hline No & & & I & \\
\hline Yes & $0.34 I(0.196-0.595)$ & $<0.001$ & $0.245(0.119-0.501)$ & $<0.001$ \\
\hline \multicolumn{5}{|l|}{ Age (years old) } \\
\hline$<60$ & & & 1 & \\
\hline$\geq 60$ & I.07। (0.627-I.830) & 0.800 & $0.748(0.385-1.455)$ & 0.393 \\
\hline \multicolumn{5}{|l|}{ Number } \\
\hline $\mathrm{I}-3$ & I & & I & \\
\hline$>3$ & $2.984(1.569-5.673)$ & 0.001 & $2.823(1.254-6.356)$ & 0.012 \\
\hline \multicolumn{5}{|l|}{ Size } \\
\hline $\mathrm{I}-5 \mathrm{~mm}$ & & & I & \\
\hline $6-9 \mathrm{~mm}$ & $1.445(0.624-3.345)$ & 0.390 & I.87। (0.676-5.175) & 0.228 \\
\hline$\geq 10 \mathrm{~mm}$ & $3.920(1.635-9.395)$ & 0.002 & $6.103(2.089-17.832)$ & 0.001 \\
\hline \multicolumn{5}{|l|}{ Site } \\
\hline Left hemicolon & 1 & & I & \\
\hline Right hemicolon & $0.84 \mid(0.4 \mid 5-1.706)$ & 0.631 & $1.257(0.528-2.990)$ & 0.605 \\
\hline Whole colon & $2.134(1.126-4.046)$ & 0.020 & $1.605(0.728-3.540)$ & 0.241 \\
\hline \multicolumn{5}{|l|}{ Pathology of adenoma } \\
\hline Tubular adenoma & 1 & & 1 & \\
\hline Villous adenoma & $4.231(1.139-15.713)$ & 0.031 & 1.941 (0.469-8.037) & 0.360 \\
\hline Mixed adenoma & $4.45 \mid(1.837-10.782)$ & 0.001 & $3.160(1.116-8.946)$ & 0.030 \\
\hline \multicolumn{5}{|l|}{ Adenoma morphology } \\
\hline Artie & $\mathrm{I}$ & & 1 & \\
\hline Pedicle & $1.023(0.363-2.879)$ & 0.966 & $1.468(0.43 \mathrm{I}-5.00 \mathrm{I})$ & 1.468 \\
\hline Flat eminence & $2.167(0.915-5.132)$ & 0.079 & $6.715(2.252-20.023)$ & 0.001 \\
\hline
\end{tabular}

system showed that the information in the current data had been fully extracted and the model has a high fitness of goodness. The model has an accuracy of $71 \%$ in predicting recurrence in the modeling cohort, and the area under the ROC curve (AUC) was 0.806 (95\% CI: 0.748-0.864). The prediction accuracy in the model validation cohort was 69\%, and the AUC was 0.771 (95\% CI: 0.694-0.847). The calibration chart was used to evaluate the consistency between the prediction effect of the model and the actual observation (the closer the blue dot to the diagonal line, the higher the consistency of the model prediction) (Figure 2). The results suggested that the model in this study was far away from the diagonal when predicting a low probability of recurrence, indicating that the accuracy of the model in predicting no recurrence needed to be improved.

\section{Discussion}

How to reduce the recurrence of colorectal adenomas and accurately assess the risk of adenoma recurrence has always been a current research hotspot. Therefore, we carried out a retrospective case-control study with additional Chinese medicine as the main exposure factor, and we initially established the risk scoring system of the recurrence of colorectal adenomas. The recurrence rates of adenomas obtained from different studies vary greatly. In this study, the recurrence rate of rectal polyps in the treatment group was $45.5 \%$ and that in the control group was $61.7 \%$, which was higher than the 


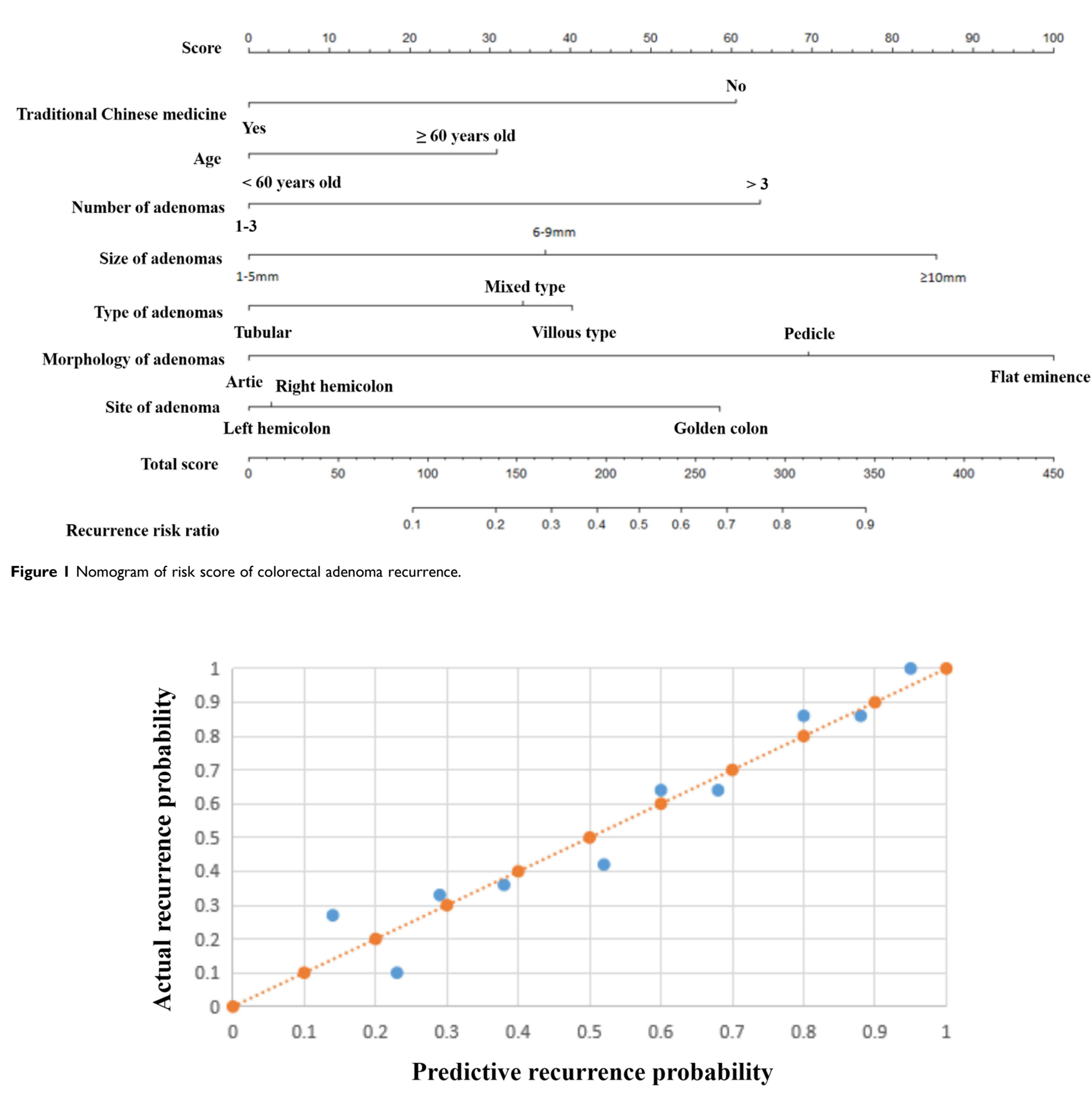

Figure 2 Calibration of risk score model.

reported 10\% 50\% in the literature. ${ }^{13,16}$ The size of adenoma of the $83.8 \%$ patients was mostly larger than $6 \mathrm{~mm}$ in our study.

The "Consensus Opinions on the Prevention of Colorectal Cancer in China (2016, Shanghai)" proposed that drugs derived from natural plants to prevent the recurrence of colorectal adenomas are worthy of in-depth study. ${ }^{17}$ We have carried out research on the prevention of colorectal adenoma recurrence with Chinese traditional medicine for more than ten years, and proposed the concept of preventing adenoma recurrence with Chinese medicine. ${ }^{18}$ We have accumulated many years of experience and formed a special prescription for preventing and treating the recurrence of colorectal adenoma, and have carried out a number of studies to confirm its effectiveness. ${ }^{15,19,20}$ This study also further confirmed that traditional Chinese medicine can reduce the recurrence of colorectal adenomas. The recurrence probability of patients taking traditional Chinese medicine is 0.245 times than that of patients not taking traditional Chinese medicine. During the follow-up, the patient's compliance was good. No serious adverse events were observed, and the safety was good. At 
the same time, all patients have not used drugs (aspirin, folic acid, vitamin D, calcium, etc.) that have potential for the treatment of colorectal adenoma, which rule out confounding factors among drugs and further consolidate the reliability of the conclusion.

In order to compare whether there are statistical differences in the demographic characteristics between the model cohort and the model validation cohort, we conducted an $\chi^{2}$-test and found that the recurrence rate of patients aged $\geq 60$ years in the model validation cohort was relatively high, but there were no similar conclusions in the modeling cohort and entire cohort. Whether traditional Chinese medicine has the same effect on patients of different genders and ages is the category of subgroup analysis. Previous studies also believe that Berberine may be more effective in reducing the recurrence of adenoma in female patients. ${ }^{14}$ In this study, the subgroup analysis of age in the model validation cohort was an exploratory postanalysis. There are limitations, such as insufficient sample size and lack of multiple adjustments. Therefore, it is not yet considered that traditional Chinese medicine has different effects on patients of different ages.

Our study further established a risk score system for the risk factors that affect the recurrence of rectal adenoma. Previous study ${ }^{1}$ believed that advanced adenomas are more likely to recur. The definition of advanced adenomas includes the size and pathological type of adenoma. In order to avoid the influence of multicollinearity in statistics, ${ }^{21}$ we treated the size and pathological type of adenoma as independent risk factors. In the multivariate analysis of the model cohort, we found that whether taking traditional Chinese medicine, the number, size, pathological type and morphology of the adenoma are independent factors affecting recurrence. After combining the baseline data difference of the model validation cohort and the univariate analysis result of the modeling cohort, we included 7 risk factors including age, drug, number, size, site, pathological type and morphology of adenoma to establish a risk scoring system and make a nomogram.

Most clinical studies believe that adenoma size is an independent factor affecting recurrence. ${ }^{22,23}$ Facciorusso et al believe that the recurrence rate of adenoma in patients with lesion diameter $\geq 15 \mathrm{~mm}$ is as high as $57.9 \%$, ${ }^{24}$ which is basically consistent with our research. The size of adenoma depends on the time of its existence and the rate of cell proliferation, and the reason for its effect on recurrence is not fully clear. Some studies have suggested that patients with adenoma size of $\geq 1 \mathrm{~cm}$ have faster proliferation rate of adenoma, thus affecting the recurrence. ${ }^{25}$ Like most studies, we believe that the pathological type and number of adenomas are important factors affecting recurrence. ${ }^{26,27}$ On the other hand, the whole colon distribution and the flat morphology of adenoma also affect its recurrence, which is related to missed diagnosis during examination. ${ }^{28,29}$

There are also some limitations in this study. The retrospective case-control method is used in the study, and the level of evidence is limited, which affects the extrapolation of conclusions. The sample size is not large enough, resulting in the larger OR value of some factors and the 95\% CI is too wide. There is a lack of multi-center external verification for further evaluation of the scoring system, which needs to be further improved by the participation of multi-centers and the expansion of samples.

\section{Conclusion}

In conclusion, the risk score system of the recurrence of colorectal adenoma established in this study has high predictive value and can be widely used in clinical practice.

\section{Data Sharing Statement}

The datasets used and/or analyzed during the current study are available from the corresponding author on reasonable request.

\section{Ethics Statement}

This study was approved by the ethics committee of the Second Affiliated Hospital of Guangzhou University of traditional Chinese (No.TSAHGU-93) and complied with the guidelines outlined in the declaration of Helsinki were followed. The written consent was received from all participants.

\section{Funding}

Special funding for clinical research of Guangdong Provincial Hospital of Traditional Chinese Medicine (No. YN10101914) and Guangzhou University of Chinese Medicine "Double First -Class" and High-level University Discipline Collaborative Innovation Team (2021xk58).

\section{Disclosure}

The authors report no conflicts of interest in this work.

\section{References}

1. Winawer SJ, Zauber AG, Fletcher RH, et al. Guidelines for colonoscopy surveillance after polypectomy: a consensus update by the US Multi-Society Task Force on Colorectal Cancer and the American Cancer Society. Gastroenterology. 2006;130(6):1872-1885. doi:10.1053/j.gastro.2006.03.012 
2. Belderbos TD, Leenders M, Moons LM, et al. Local recurrence after endoscopic mucosal resection of nonpedunculated colorectal lesions: systematic review and meta-analysis. Endoscopy. 2014;46:388-402. doi:10.1055/s-0034-1364970

3. Reid ME, Marshall JR, Roe D, et al. Smoking exposure as a risk factor for prevalent and recurrent colorectal adenomas. Cancer Epidemiol Biomarkers Prev. 2003;12:1006-1011.

4. Jacobson JS, Neugut AI, Murray T, et al. Cigarette smoking and other behavioral risk factors for recurrence of colorectal adenomatous polyps (New York City, NY, USA). Cancer Causes Control. 1994;5:215-220. doi:10.1007/BF01830239

5. Schatzkin A, Lanza E, Corle D, et al. Lack of effect of a lowfat, high-fiber diet on the recurrence of colorectal adenomas. Polyp prevention trial study group. $N$ Engl J Med. 2000;342:1149-1155. doi:10.1056/NEJM200004203421601

6. Sansbury LB, Wanke K, Albert PS, et al. The effect of strict adherence to a high-fiber, high-fruit and -vegetable, and low-fat eating pattern on adenoma recurrence. Am $J$ Epidemiol. 2009;170:576-584. doi:10.1093/aje/kwp169

7. Alberts DS, Martínez ME, Roe DJ, et al. Lack of effect of a highfiber cereal supplement on the recurrence of colorectal adenomas. Phoenix colon cancer prevention physicians' network. $N$ Engl J Med. 2000;342:1156-1162. doi:10.1056/NEJM200004203421602

8. Meyerhardt JA, Niedzwiecki D, Hollis D, et al. Association of dietary patterns with cancer recurrence and survival in patients with stage III colon cancer. JAMA. 2007;298:754-764. doi:10.1001/jama.298.7.754

9. Higurashi T, Hosono K, Takahashi H, et al. Metformin for chemoprevention of metachronous colorectal adenoma or polyps in post-polypectomy patients without diabetes: a multicentre double-blind, placebo-controlled, randomised Phase 3 trial. Lancet Oncol. 2016;17:475-483. doi:10.1016/S1470-2045(15)00565-3

10. Baron JA, Cole BF, Sandler RS, et al. A randomized trial of aspirin to prevent colorectal adenomas. $N$ Engl J Med. 2003;348:891-899. doi:10.1056/NEJMoa021735

11. Veettil SK, Lim KG, Ching SM, et al. Effects of aspirin and non-aspirin nonsteroidal anti-inflammatory drugs on the incidence of recurrent colorectal adenomas: a systematic review with meta-analysis and trial sequential analysis of randomized clinical trials. BMC Cancer. 2017;17:763. doi:10.1186/s12885-017-3757-8

12. Baron JA, Barry EL, Mott LA, et al. A trial of calcium and vitamin D for the prevention of colorectal adenomas. $N$ Engl $J$ Med. 2015;373:1519-1530. doi:10.1056/NEJMoa1500409

13. Gao QY, Chen HM, Chen YX, et al. Folic acid prevents the initial occurrence of sporadic colorectal adenoma in Chinese older than 50 years of age: a randomized clinical trial. Cancer Prev Res. 2013;6:744-752.

14. Chen Y-X, Gao Q-Y, Zou T-H, et al. Berberine versus placebo for the prevention of recurrence of colorectal adenoma: a multicentre, double-blinded, randomised controlled study. Lancet Gastroenterol Hepatol. 2020;5:267-275. doi:10.1016/S2468-1253(19)30409-1

15. Beiping Z, Xiying Z, Gang L. Study on traditional Chinese medicine intervention of adenomatous colorectal polyps based on the theory of "preventive treatment". Chin Gen Med. 2012;15(23):2718-2720.
16. Gao Q, Chen H, Sheng J, et al. The first year follow-up after colorectal adenoma polypectomy is important: a multiple-center study in symptomatic hospital-based individuals in China. Front Med China. 2010;4(4):436-442. doi:10.1007/s11684-010-0200-9

17. Shi X, Yang Z, Wu Q, et al. Colorectal adenoma recurrence rates among post-polypectomy patients in the placebo-controlled groups of randomized clinical trials: a meta-analysis. Oncotarget. 2017;8 (37):62371-62381. doi:10.18632/oncotarget.18181

18. Chinese Medical Association Gastroenterology Branch, Chinese Medical Association Gastroenterology Branch Cancer Cooperation Group. China Colorectal Cancer Prevention Consensus (2016, Shanghai). Chin J Digest. 2016;21(11):668-686.

19. Ling ZC, Ling WA, Ying ZX, et al. Progress in the treatment of colorectal adenomatous polyp recurrence after operation. Chin J Integr Chin West Med Digest. 2019;27(12):956-961.

20. Li Y, Yisheng S, Beiping Z, et al. Luo Yunjian's experience in prevention and treatment of recurrence of colorectal polyps. J Pract Chin Med. 2018;34(12):1533-1534.

21. Tianwen L, Yan C. Characteristics of TCM syndrome types in patients with colorectal polyps. Chin $J$ Traditional Chin Med. 2010;28(07):1562-1564.

22. Fei Z. Diagnosis and improvement of multicollinearity of logistic regression and its application in medicine. Lanzhou University; 2011.

23. Chung SJ, Kim YS, Yang SY, et al. Five-year risk for advanced colorectal neoplasia after initial colonoscopy according to the baseline risk stratification: a prospective study in 2452 asymptomatic. Gut. 2011;60(11):1537-1543. doi:10.1136/gut.2010.232876

24. Viel JF, Studer JM, Ottignon Y, et al. Predictors of colorectal polyp recurrence after the first polypectomy in private practice settings: a cohort study. PLoS One. 2012;7(12):e50990. doi:10.1371/journal. pone. 0050990

25. Facciorusso A, DI MASO M, Serviddio G, et al. Factors associated with recurrence of advanced colorectal adenoma after endoscopic resection. Clin Gastroenterol Hepatol. 2016;14(8):1148-1154. doi:10.1016/j.cgh.2016.03.017

26. Noshirwani KC, van Stolk RU, Rybicki LA, et al. Adenoma size and number are predictive of adenoma recurrence: implications for surveillance colonoscopy. Gastrointest Endosc. 2000;51:433-437. doi:10.1016/S0016-5107(00)70444-5

27. Lieberman DA, Rex DK, Winawer SJ, et al. Guidelines for colonoscopy surveillance after screening and polypectomy: a consensus update by the US multisociety task force on colorectal cancer. Gastroenterology. 2012;143:844-857. doi:10.1053/j.gastro.2012.06.001

28. Miller HL, Mukherjee R, Tian J, et al. Colonoscopy surveillance after polypectomy may be extended beyond five years. J Clin Gastroenterol. 2010;44:e162-6. doi:10.1097/MCG.0b013e3181e5cd22

29. van Rijn JC, Reitsma JB, Stoker J, et al. Polyp miss rate determined by tandem colonoscopy: a systematic review. Am J Gastroenterol. 2006;101(101):343-350. doi:10.1111/j.1572-0241.2006.00390.x
Risk Management and Healthcare Policy

\section{Publish your work in this journal}

Risk Management and Healthcare Policy is an international, peerreviewed, open access journal focusing on all aspects of public health, policy, and preventative measures to promote good health and improve morbidity and mortality in the population. The journal welcomes submitted papers covering original research, basic science, clinical \& epidemiological studies, reviews and evaluations, guidelines, expert opinion and commentary, case reports and extended reports. The manuscript management system is completely online and includes a very quick and fair peer-review system, which is all easy to use. Visit http://www.dovepress.com/testimonials.php to read real quotes from published authors. 